\title{
A humanização da assistência em enfermagem no cuidado ao paciente: percepção dos enfermeiros de dois hospitais do interior do estado do Rio Grande do Sul
}

The humanization of nursing care in patient care: perception of nurses from two hospitals in the interior of the state of Rio Grande do Sul

La humanización de la atención de enfermería en la atención al paciente: percepción de las enfermeras de dos hospitales del interior del estado de Rio Grande do Sul

Recebido: 11/10/2021 | Revisado: 16/10/2021 | Aceito: 07/01/2022 | Publicado: 10/01/2022

\author{
Andrieli Franzon \\ ORCID: https://orcid.org/0000-0003-4882-2057 \\ Universidades do Vale do Taquari, Brasil \\ E-mail: andrieli.franzon@universo.univates.br \\ Paula Michele Lohmann \\ ORCID: https://orcid.org/0000-0002-8429-9155 \\ Universidades do Vale do Taquari, Brasil \\ E-mail: paulalohmann@univates.br \\ Arlete Eli Kunz da Costa \\ ORCID: https://orcid.org/0000-0002-5655-3646 \\ Universidades do Vale do Taquari, Brasil \\ E-mail: arlete.costa@univates.br \\ Eliane Lavall \\ ORCID: https://orcid.org/0000-0002-6439-2117 \\ Universidades do Vale do Taquari, Brasil \\ E-mail: eliane.lavall@univates.br
}

\begin{abstract}
Resumo
O termo humanização vem ganhando destaque na área da saúde, em especial na enfermagem, pois ela é quem passa a maior parte do tempo prestando assistência ao paciente. Sabendo da importância de fornecer um atendimento humanizado, percebe-se a necessidade de evidenciar como os enfermeiros significam a humanização, e quais condutas aplicam em seu cotidiano. O objetivo deste estudo é compreender como condutas humanizadas na assistência de enfermagem, podem contribuir na melhora do paciente, na percepção de enfermeiros de dois hospitais no interior do estado do Rio Grande do Sul. Trata-se de uma pesquisa qualitativa descritiva, na qual foram entrevistados sete enfermeiros atuantes nos hospitais de dois pequenos municípios por meio de um instrumento elaborado pela pesquisadora. Os principais resultados demonstram que os enfermeiros conhecem e significam o termo humanização, de acordo com suas vivências e percepções cotidianas, além de empregarem condutas que consideram humanizadas no dia a dia. Apontam como fatores dificultantes sobrecarga de trabalho, baixa remuneração, excesso de demanda, e falta de profissionais, acreditam que uma assistência humanizada pode sim contribuir na melhora do paciente. Concluímos que os profissionais se mostraram satisfeitos com o trabalho que vem sendo realizado por eles, mas que ainda poderiam ser feitas melhorias, para os fatores apontados como dificultantes, também é importante manter e oportunizar, a educação permanente e constante em saúde, abrindo espaços para uma discussão sobre o que já é feito, e o que pode ser melhorado, para o bom funcionamento dos serviços.
\end{abstract}

Palavras-chave: Cuidado; Enfermagem; Humanização dos serviços.

\begin{abstract}
The term humanization has been gaining prominence in the health area, especially in nursing, because it is the one who spends most of the time providing care to the patient. Knowing the importance of providing humanized care, one perceives the need to show how nurses mean humanization, and what behaviors they apply in their daily lives. The aim of this study is to understand how humanized conducts in nursing care can contribute to patient improvement, in the perception of nurses from two hospitals in the interior of the state of Rio Grande do Sul. This is a descriptive qualitative research, in which seven nurses working in hospitals in two small municipalities through an instrument elaborated by the researcher. The main results show that nurses know and signify the term humanization, according to their daily experiences and perceptions, in addition to employing conducts that they consider humanized in everyday life. They point out as hindering factors work overload, low pay, excessive demand, and lack of professionals, believe that humanized care can contribute to the improvement of the patient. We conclude that the professionals were satisfied with
\end{abstract}


the work that has been carried out by them, but that improvements could still be made, for the factors pointed out as hindering factors, it is also important to maintain and provide opportunities, permanent and constant education in opening spaces for a discussion about what is already done, and what can be improved, for the proper functioning of services.

Keywords: Beware; Nursing; Humanization of services.

\section{Resumen}

El término humanización ha ido ganando protagonismo en el área de la salud, especialmente en enfermería, pues es quien pasa la mayor parte del tiempo brindando atención al paciente. Conociendo la importancia de brindar cuidados humanizados, se percibe la necesidad de mostrar cómo las enfermeras significan humanización, y qué comportamientos aplican en su vida diaria. El objetivo de este estudio es comprender cómo las conductas humanizadas en la atención de enfermería pueden contribuir a la mejora del paciente, en la percepción de las enfermeras de dos hospitales del interior del estado de Rio Grande do Sul. Se trata de una investigación cualitativa descriptiva, en la que se entrevistó a siete enfermeras que trabajan en hospitales de dos pequeños municipios a través de un instrumento elaborado por el investigador. Los principales resultados muestran que las enfermeras conocen y significan el término humanización, de acuerdo con sus experiencias y percepciones cotidianas, además de emplear conductas que consideran humanizadas en la vida cotidiana. Señalan como factores difíciles la sobrecarga de trabajo, la baja retribución, la demanda excesiva, y la falta de profesionales, creen que la atención humanizada puede contribuir a la mejora del paciente. Concluimos que los profesionales quedaron satisfechos con el trabajo que se ha realizado por ellos, pero que aún se podrían hacer mejoras, por los factores señalados como difíciles, también es importante mantener y brindar oportunidades, educación permanente y constante en salud, abriendo espacios para una discusión sobre lo que ya se ha hecho, y lo que se puede mejorar, para el buen funcionamiento de los servicios.

Palabras clave: Cuidado; Enfermería; Humanización de servicios.

\section{Introdução}

Para o Ministério da Saúde (Ministério da Saúde, 2020), a humanização pode ser definida como a valorização dos gestores, usuários e trabalhadores na formação da elaboração da saúde. A valorização e o reconhecimento dos indivíduos proporcionam maior autonomia, e desenvolvimento da sua habilidade de transformar a realidade em que vivem, por meio da responsabilidade conjunta, seja na criação de vínculos solidários, ou na atuação coletiva nos métodos de gestão e de produção de saúde.

O atendimento humanizado, independentemente da situação, deve valorizar o respeito afetuoso ao outro, e prestigiar a melhoria de vida e das relações entre as pessoas em geral. Humanizar a assistência prestada é adotar práticas na qual o profissional respeite o paciente considerando-o como um ser independente e digno (De Moura et al., 2014).

Tendo em vista que o atendimento humanizado inicia na recepção do paciente, no momento em que nos preocupamos com o período que ele vai aguardar, no fornecimento de senhas, disposição de cadeiras para que aguarde ser chamado de modo mais confortável. Assim a humanização se revela no modo como acolhemos o paciente no setor, quando provemos informações referentes a regras e rotinas da instituição de saúde, na resolução de dúvidas ou questões pertinentes a realização de procedimentos, e até mesmo na imagem pessoal do profissional de saúde, uma vez que quando nos observam constatam, se temos capacidade de cuidar deles (Simões et al., 2007).

Em seus estudos Chernicharo et al., (2013) concluíram que a percepção sobre humanização no cuidado, está irrefutavelmente conectada com quesitos de empatia entre profissionais e usuários. Sendo uma ferramenta relevante no processo de humanização, na medida em que o indivíduo passa a se imaginar no lugar do outro, quando passa a pensar como se sentiria se estivesse na situação vivenciada pelo outro, aderindo então a adoção de uma conduta de acordo com seus valores e princípios, qualificando o cuidado prestado.

A humanidade pode ser demonstrada principalmente pelo cuidado, contudo cuidar exige amor, amizade e cura, percebemos então que a cura não provém unicamente do processo técnico-curativo, mas essencialmente do sentimento abrangente de afeto e amor, explícitos no cuidado. Deste modo, cuidar é conceder da própria humanidade para assistir ao outro, considerando que se trata de uma pessoa única, em suas esferas físicas, mentais, emocionais, com desejos e vontades. Nos 
referimos a seres pensantes, providos de dignidade, a serem cuidados em sua completude, deste modo o cuidado está alicerçado numa relação inter-humana (Corbani et al., 2009).

A enfermagem manifesta-se como uma junção entre quem irá cuidar e o ser cuidado, podendo ressaltar que esta profissão executa um papel indispensável na prática do cuidar humanizado, por meio de uma interação verdadeira com o paciente hospitalizado. Possibilitando assim uma comunicação genuína, de forma a propor a formação de espaços que proporcionem a satisfação do ser doente, contemplando suas necessidades, quando possibilitado a dividir suas vivências, angústias, medos, ansiedades e inseguranças. Nessa perspectiva o cuidado, como uma prática assistencial humanizada, deve estar focado na comunicação como um meio para aproximar o profissional do paciente (Morais et al., 2009).

A humanização é portanto uma transformação das estruturas, na maneira de trabalhar e também das pessoas, assim o trabalho em saúde se humaniza quando alcançamos a associação da manutenção de uma vida mais longa, aliada a formação de novos padrões na qualidade de vida para sujeitos reais, para isso é indispensável a colaboração mútua entre profissional e paciente (Campos, 2005).

Durante minha trajetória acadêmica, pude presenciar a assistência em enfermagem de várias formas, às vezes de forma humanizada, onde era evidente o zelo, a empatia, e o respeito mútuo. Em outras ocasiões também presenciei atendimentos não humanizados, na maioria das vezes caracterizados pela pressa, excesso de demanda, estresse, rotina exaustiva da equipe de enfermagem. De modo que a assistência se tornava insatisfatória, tanto para o usuário, que muitas vezes não tinha suas necessidades atendidas, e para o profissional, que acabava frustrado por não conseguir atender a todas as demandas.

Diante do exposto, surge a seguinte questão: Quais condutas podem ser aplicadas a fim de contribuir para uma assistência humanizada e efetiva, com foco na empatia e melhora dos pacientes? Este estudo justifica-se principalmente por minha curiosidade, durante o decorrer de minha trajetória acadêmica, em compreender como a assistência humanizada em enfermagem pode melhorar a qualidade de vida dos pacientes, implementação de novas condutas e hábitos, que sejam capazes de transformar a qualidade da assistência prestada.

Com este estudo, esperamos evidenciar como a equipe de enfermagem pode atuar para melhorar o bem-estar dos pacientes, através de condutas humanizadas na assistência, dificuldades e obstáculos que o impeçam de ser feito, aliado às estratégias de cuidado e condutas empregadas com os pacientes, visando contribuir para uma sensibilização, e percepção da equipe a respeito do tema.

Neste sentido o tema do estudo foi a humanização da assistência em enfermagem no cuidado ao paciente. O problema de pesquisa: Quais condutas podem ser aplicadas a fim de contribuir para uma assistência humanizada e efetiva, com foco na empatia e melhora dos pacientes?

O objetivo geral é compreender como condutas humanizadas na assistência de enfermagem, podem contribuir na melhora do paciente, na percepção de enfermeiros de dois hospitais no interior do estado do RS.

\section{Fundamentação Teórica}

\subsection{Caracterização da humanização e do atendimento humanizado}

A humanização na sua definição formal se expressa na ação/efeito de humanizar, que se esclarece em conceder meios, forma e condição humana, fazer-se bondoso, afetuoso, sensível, caridoso (Fernandes \& Luft, 2000). À medida que nos referimos a humanização nas relações interpessoais, podemos rever os sentidos denotativos da palavra, compreender a humanização como algo inerente ao ser humano, um sentimento espontâneo, tendo o bem como princípio para nortear as relações em sociedade (Chernicharo et al., 2014).

Conforme Alves (2012) na área da saúde, a humanização teve a primeira abordagem por volta da década de 80, no momento que esse termo começou a alcançar relevância e adeptos, em razão das conformidades na luta antimanicomial, pela 
reforma psiquiátrica na área da Saúde Mental, também na área da Saúde da Mulher, no ato feminista durante a busca pela humanização do parto e do nascimento. Na área obstétrica, este movimento tomou forma quando foram postas em prática mudanças no decorrer de procedimentos, como proporcionar o contato direto pele a pele da mãe para com seu bebê. A princípio esse processo transformador, foi visto com certa recusa e negação pelos profissionais de saúde (Wei et al., 2012).

Estas referências emergiram trazendo impactos consideráveis, que transformaram estes momentos em demarcações históricas, e deram início ao debate na busca pela humanização, no campo da saúde (Chernicharo et al., 2014).

A partir de então, lentamente os hospitais iniciaram a formulação e aplicação de condutas consideradas humanizadas, que a princípio tinham o objetivo de transformar o ambiente hospitalar, diante da execução de atividades lúdicas, entretenimento, arte e melhorias na apresentação estrutural dos serviços. Estas ações agiam como uma alternativa para reduzir o sofrimento causado pelo ambiente de trabalho hospitalar, aos poucos o plano obteve concordância, que resultou em mudanças no cotidiano, por exemplo: liberação de visitas livres, presença de acompanhante, opção de dieta personalizada (Rios, 2009).

Gradativamente, a temática de humanização na assistência de enfermagem conquista seu espaço no campo da saúde, de modo a torna-se fundamental entender como essa questão vem sendo aperfeiçoada nos diferentes cenários de trabalho da enfermagem, revelando quais significações e sentidos os profissionais de enfermagem vem atribuindo ao vocábulo humanização e como tais conceitos reverberam em suas práticas cotidianas (Chernicharo et al., 2014).

Em seus estudos Volich (1995), constatou que o fato de identificar a relevância das particularidades humanas constitui o passo primordial para a humanização, o segundo passo é elaborar estratégias que facilitem a inclusão destes fatores humanos, na forma de pensar e agir nas práticas de saúde, adoecimento e cura nas relações de trabalho. Esse processo pode ser percebido por meio do desenvolvimento de espaços autênticos de fala e escuta que conduzam à palavra de forma transformadora.

Na relação do profissional e paciente, a escuta não é unicamente uma ação generosa e de prestatividade, mas um recurso técnico essencial para o diagnóstico preciso e adaptação terapêutica. Estes ambientes são a essência para a execução da gestão participativa e da transdisciplinaridade na atuação conjunta (Rios, 2009). Assim os profissionais de enfermagem tem a possibilidade de empregar a comunicação como um modo de humanizar o cuidado, conversando com o paciente, solucionando dúvidas, demandas, referentes ao seu tratamento, exames diagnósticos ou procedimentos clínicos, de modo a reduzir a ansiedade decorrente de sua condição exigida pela doença e hospitalização (Morais et al., 2009).

É perceptível que o compromisso com o acolhimento das demandas e necessidades dos usuários, aliados à criação de vínculos norteados pelo respeito à autonomia e as diferenças, integram princípios indispensáveis na proposta de humanização em saúde. Assim, é preciso estabelecer um novo patamar ético e tecnológico das práticas em saúde, nesse processo é necessário buscar o equilíbrio entre responsabilização e respeito à autonomia, ou entre aproximação e respeito à privacidade (Deslandes, 2006).

\subsection{O enfermeiro e o processo de humanização}

A humanização como processo nas instituições de saúde emerge para que o profissional possa refletir e rever suas práticas cotidianas de trabalho, atribuindo um novo sentido para a assistência (Cavalcante et al., 2013).

Na enfermagem, o cuidado e a humanização alcançam grande significância, pois se fundamentam em práticas nas quais se lida com o ser humano, nos mais diversos cenários de vulnerabilidade. Portanto suas práticas transcendem as habituais de natureza mais técnica, e com finalidades quase que unicamente terapêuticas. Desta forma, o ser humano passa a ser percebido e assistido de modo integral em sua subjetividade (Waldow \& Borges, 2011).

Oliveira et al. (2013) acreditam que enquanto profissionais de saúde, só podemos falar em cuidado humanizado, se nós percebemos responsáveis pelo contentamento das demandas de saúde dos pacientes. Assim é essencial ao enfermeiro, tentar visualizar seus pacientes como indivíduos que carregam consigo uma história/identidade, e não meramente alvos do cuidar. 
Para Callegari et al. (2015) os conceitos de humanização e acolhimento se encontram e entrelaçam, pois acolher remete escutar, conceder proteção, abrigo e conforto. Para poder acolher é fundamental que o profissional, possua uma condição emocional de acessibilidade, permitindo-se sensibilizar-se pela história do paciente, suas demandas e anseios, despertando um envolvimento além do processo técnico, referente a humanização. Movido pela vontade de atender e resolver demandas e necessidades.

A compreensão da equipe de enfermagem acerca da relevância de reconhecer a singularidade de cada paciente, contribui para que seus anseios sejam minimizados. É fundamental visualizar toda a situação do paciente, de modo integral, objetivando não somente recuperar seu bem-estar físico, mas captar suas emoções, frustrações e vontades, na aspiração de poder sair da condição em que se encontra curado (Gallo \& Mello, 2009).

Muitas vezes os profissionais não conseguem se sentir de fato envolvidos com o paciente, que na consequência de sua enfermidade encontra-se esmaecido e abalado. Para efetivamente humanizar a assistência, é imprescindível possuir uma formação de qualidade, todavia estar sozinha ainda não é suficiente, é preciso desenvolver características capazes de prezar pela ética humanitária. Deste modo a humanização só será realmente compreendida quando os profissionais de saúde entenderem a relevância de sua atribuição neste contexto, seja prestando cuidados durante o processo de enfermidade e reabilitação, ou mesmo na ocorrência de uma morte digna (Simões et al., 2007).

\subsection{Políticas de humanização}

$\mathrm{Na}$ enfermagem a humanização abrange tanto o nível micro, alusivo à assistência, quanto no nível macro, referente a gestão e as políticas públicas, entendendo que para transformar a realidade, é fundamental que sejam evidenciados obstáculos, ou fatores dificultantes presentes no setor da saúde, que inviabilizem uma assistência integral e humana, incumbindo a todos os integrantes a elaboração e implementação de estratégias competentes, tendo como objetivo uma assistência competente, efetiva, qualificada e humanizada (Chernicharo et al., 2014).

O tema da humanização veio à tona na forma de programa do Ministério da Saúde, dirigido para a atenção hospitalar no ano de 2001, tendo como meta promover o atendimento aos usuários e trabalhadores de Saúde. Essa necessidade mostrou-se com falta de esperança do Sistema Único de Saúde (SUS) pela população, somada aos diversos problemas que abrangiam a execução e implementação das políticas de saúde. No ano de 2003 a humanização se torna política nacional, tendo como alvo a implementação dos princípios e das diretrizes referentes à Lei Orgânica da Saúde (Palheta \& Costa, 2012).

Estão inclusas nas diretrizes do Humaniza SUS, o acolhimento, ambiência, gestão participativa, clínica ampliada e compartilhada, cogestão, valorização do trabalhador, e a defesa dos direitos dos usuários, essenciais para uma assistência benéfica aos usuários. Estas podem se fazer presentes através da realização de uma escuta efetiva, atendendo e solucionando demandas do usuário, incluindo os indivíduos na análise e decisão das tarefas da gestão, na criação de ambientes receptivos e hospitaleiros, na qualificação do diálogo entre a equipe, na orientação e prestação de informação ao usuário quanto a sua saúde (Ministério da Saúde, 2020).

Como estratégia para valorizar presença de profissionais, usuários, e gestores o Ministério da Saúde (Ministério da Saúde, 2020) propõe a criação e promoção de rodas de conversa, estímulo e incentivo às ações sociais, inclusão dos trabalhadores no método de gestão, visto que quando compreendem as dificuldades vivenciadas, efetivam mudanças em sua rotina laboral, e na administração de setores. Essa inclusão de usuários e seus respectivos familiares nesse processo de saúde, acarreta a extensão na responsabilização do cuidado.

Quando presente no contexto brasileiro, as Políticas Públicas de Humanização (PNH) sugere várias transformações para a concretização da saúde na qualidade de direito social da população, visto na passagem constitucional de 1988 e também nas Leis 8080/90 e 8142/90. Consequentemente o enaltecimento e valorização dos indivíduos, gestores, usuários, ou trabalhadores, 
considera as questões intrínsecas envolvidas na construção da saúde. O protagonismo dos indivíduos implicados na PNH se faz indispensável para o seguimento de democratização da saúde, conforme os princípios do SUS, na universalidade, equidade e integralidade, direcionados à construção da cidadania (Palheta \& Costa, 2012).

Neste contexto o tópico das Políticas Públicas de Humanização, com destaque para a realidade brasileira, necessita de grandes debates, sobre a execução da PNH, que se mostra como um importante ponto de referência para a construção de práticas de saúde que incentivem o respeito ao cidadão, incluindo seus princípios, desejos, aspirações, demandas e necessidades. É imprescindível então desenvolver mais investigações, uma vez que irá propiciar uma consolidação nas opiniões e nas críticas sobre o tema em pauta (Moreira et al., 2015).

\subsection{0 conceito de desumanização em saúde}

As atuais mudanças no campo da saúde revelam impactos positivos e negativos, de um lado a obtenção de relevantes avanços na aceleração e ampliação no diagnóstico, intervenções terapêuticas precocemente, com precisão e segurança, de outro lado evidencia-se a automatização e severidade nos exames complementares, excessivo direcionamento do paciente em órgãos e funções, aliado ao intervencionismo exagerado, os altos custos de procedimentos diagnósticos e terapêuticos, e falta de atenção nos aspectos psicossociais do paciente, resultam em nítidas barreiras (Ayres, 2006).

Um dos primeiros significados da desumanização seria o de despersonalizar o paciente, apontando a insistente ação de caracterizar o doente como meio de intervenção clínica, deixando de vê-lo de forma integral, como um todo. Neste entendimento as pessoas doentes seriam de certa forma um conjunto de necessidades padronizadas, a serem atendidas por serviços igualmente formais. Essa conduta apresenta como consequência a ausência de poder pelo paciente doente, e o não reconhecimento de suas emoções, a humanização do cuidado se apoiaria em uma relação que presume a igualdade em algum nível, convicções de inferioridade ou superioridade seriam contrárias a cuidado humanizado (Deslandes, 2006).

Situações consideradas desumanizantes podem ser identificadas na forma de comentários inoportunos, barulhos constantes, falta de privacidade do paciente, utilização de estereótipos para se referir ao mesmo. Fatos estes que são vistos em muitos setores, não atribuindo apenas a tecnologia um fator da desumanização da assistência de enfermagem, se a assistência não for praticada de modo a considerar e valorizar os princípios éticos e humanos, ela dissipa sua essência em existir (Silva et al., 2011).

Nos estudos de Chernicharo et al. (2014) os profissionais definem a escassez da humanização como uma conduta mecânica, onde muitas vezes apenas veem e tratam a doença, e não o ser humano, isso se mostra presente na falta de comunicação, exercendo apenas a técnica do procedimento, a extensa jornada de trabalho, conflitos institucionais e problemas associados aos meios materiais, empregando a tecnologia em destaque, podem dificultar a qualidade da assistência prestada.

A desumanização pela tecnologia, apontaria para casos em que o cuidado seria em grande parte realizado por meio de máquinas, e procedimentos, de modo que a relação paciente/profissional seria ocasional, secundária, dispensável, e até mesmo ausente. As instâncias intrínsecas, conflitos e indagações do paciente seriam dessa forma ignoradas sistematicamente. Posteriormente, outra prática desumanizadora seria portar-se a alguns pacientes de modo desigual, levando em conta atribuições de status, hierarquia, leituras étnico-raciais, classes sociais, gênero, e outros critérios, onde se sobressairiam as pessoas consideradas com maior posição social (Deslandes, 2006).

Silva (2006) já deixava claro a sua percepção durante suas vivências, alertando para o fato que poucas vezes os pacientes realmente precisavam de medicação, na maioria das vezes eles só necessitavam de um pouco de atenção, carinho, de um sorriso amistoso e solidário, enaltecendo que o ser humano existe nas dimensões físicas mentais, emocionais e espirituais, todas são importantes e devem ser valorizadas. Para tanto na enfermagem o verbo cuidar deve exceder o significado técnico científico, 
refletindo muito mais que simplesmente, tocar ou fazer um curativo, no que constitui as questões hospitalares. $\mathrm{O}$ ato de cuidar em si, é autenticamente difundir amor, espalhar carinho, felicidade, gentilezas e bons sentimentos a quem precisa.

\section{Procedimentos Metodológicos}

Segundo Praça (2010), a metodologia científica possibilita o entendimento e análise do mundo por meio da estruturação do conhecimento. O conhecimento ocorre quando o estudante percorre sentidos do saber, tendo como protagonista deste processo o conjunto de ensino/aprendizagem. É possível fazer uma associação da metodologia com o trajeto de estudo a ser percorrido e ciência com o saber alcançado.

O modo de abordagem do estudo é de natureza qualitativa. Referente ao objetivo, a pesquisa é um estudo descritivo que empregou como procedimento técnico o levantamento de dados, de forma transversal. As pesquisas descritivas têm como propósito a exposição das particularidades de certa população a ser estudada, e a indicação de relações entre variáveis, uma de suas características mais marcantes é o uso de técnicas padronizadas na coleta de dados, tais como o questionário, observação sistemática (Gil, 2002).

A pesquisa qualitativa visa o aperfeiçoamento do entendimento de um grupo social/organização. O pesquisador que emprega o uso da abordagem qualitativa contrapõe a ideia de um modelo exclusivo de pesquisa, para quaisquer ciências, pois as ciências sociais têm sua característica, que define como uma metodologia própria (Silveira \& Córdova, 2009).

O estudo foi realizado em dois hospitais de pequeno porte situados no alto Vale do Taquari, distantes há $140 \mathrm{~km}$ de Porto Alegre, RS, que dispõem de áreas territoriais de 242, $260 \mathrm{Km}^{2}$, e 118,144 km². E em altitudes de 411 e 786 metros, no último censo a população dos dois municípios juntos se mantinha em torno de 10.000 habitantes. Composta principalmente por habitantes de origem italiana, alemã e polonesa (IBGE, 2020a , 2020b).

A escolha pelos locais de estudo, se fundamentou na necessidade de potencializar e destacar as ações de humanização na assistência, prestadas aos usuários dos serviços, promovendo uma sensibilização e ampliação nas ações dos profissionais de enfermagem frente a importância de efetivar um atendimento humanizado ao paciente.

Os participantes do estudo foram sete (7) enfermeiros, que atuam nos dois hospitais, nos três turnos de trabalho (manhã, tarde e noite). Ressalta-se que por se tratar de hospitais de pequeno porte em cada instituição, no quadro funcional havia quatro (4) enfermeiros.

A coleta de dados pode ser classificada como um dos momentos mais relevantes na realização de uma pesquisa, visto que no decorrer da coleta de dados o pesquisador adquire as informações primordiais para a produção do seu estudo. É possível afirmar que o sucesso da pesquisa está ligado ao modo que o pesquisador escolhe para realizar a coleta dos dados e, para reunir coerentemente os recursos precisos para a elaboração da pesquisa, é responsabilidade do pesquisador elencar estratégias de coleta de dados que contemplem seus objetivos e que se encontrem de acordo com a técnica utilizada (Oliveira et al., 2016).

Os enfermeiros que aceitaram participar da pesquisa foram direcionados individualmente a uma sala reservada no Hospital do município em questão. Para a entrevista foi utilizado um roteiro com perguntas pré-formuladas, a entrevista foi gravada e posteriormente transcrita.

Referente às etapas da coleta, primeiramente foi solicitada assinatura da carta de anuência da direção dos hospitais. Após a aprovação, foi efetivado contato com a coordenação dos Hospitais, para agendar as entrevistas com os enfermeiros (as) conforme disponibilidade de data e horário. No momento da coleta foi entregue aos participantes o Termo de Consentimento Livre Esclarecido (TCLE) orientado a assinar em duas vias, uma via ficou com o entrevistado e a outra com o entrevistador.

As informações obtidas foram analisadas de forma qualitativa, conforme os estudos de Bardin (2016). A pesquisa seguiu as diretrizes da Resolução nº 466, de 12 de dezembro de 2012, do Conselho Nacional de Saúde (Resolução n. 466, 2012). Os 
critérios de inclusão foram: estar atuando no Hospital, a pelo menos 90 dias; e os critérios de exclusão: não ter condições de discorrer sobre o assunto em estudo;

O pesquisador comprometeu-se a assegurar o sigilo da identidade dos participantes do estudo, utilizando letras para caracterizá-los, sendo assim foi utilizado a palavra Entrevistado seguido de letra alfabética (A, B, C) conforme ordem de entrevista apresentando apenas os resultados em eventos científicos, de forma generalizada.

\section{Análise e Discussão dos Dados}

No presente capítulo será apresentada a análise e discussão dos dados, onde o objetivo foi compreender como condutas humanizadas na assistência de enfermagem, podem contribuir na melhora do paciente, na percepção de enfermeiros de dois hospitais no interior do estado do RS.

As categorias resultantes foram as seguintes: Entendimento sobre humanização; Condutas humanizadas empregadas no cotidiano; Fatores dificultantes na assistência humanizada; Entendimento acerca do atendimento humanizado, e sua contribuição na melhora do paciente.

Primeiramente vamos apresentar as características dos informantes da pesquisa. Quanto ao sexo, seis (6) enfermeiros são do sexo feminino, um (1) enfermeiro do sexo masculino. O tempo de formação dos enfermeiros variou de um (1) a 20 anos e o tempo de atuação no hospital de um (1) a 10 anos.

\subsection{Categoria 1: Entendimento sobre humanização}

Quando questionados sobre seu entendimento acerca da humanização, percebemos que os profissionais entrevistados, relacionam o atendimento humanizado ao sentimento de empatia. Percebeu-se que os conceitos atribuídos à humanização são positivos, pois em suas falas os enfermeiros trazem como conviç̧ões, a importância da equidade no atendimento, e a empatia. Atentando-se ao fato de garantir uma assistência respeitosa e de qualidade aos pacientes. Conforme as falas que seguem:

'tratar todos os pacientes de forma igualitária, com empatia". Entrevistado E

"respeitar as diferenças de cada paciente, e tratá-lo sem distinção, se colocar no lugar do paciente". Entrevistado F

"(...) se colocar no lugar do paciente"'. Entrevistado G

Quando se levanta o tópico da empatia, logo em fusão concomitante decorre o conceito de humanização, em vista de que no momento em que o sujeito se dispõe a estar no lugar do outro, é possível portar-se e entendê-lo de acordo com as expectativas do próprio indivíduo, oportunizando uma junção de princípios e perspectivas (Chernicharo et al., 2014).

A relutância em possuir sentimentos de empatia, seja por razões ou entraves pessoais, pode gerar lacunas na relação entre profissionais e pacientes e, em decorrência, não colaborar para um cuidado íntegro e atencioso, assim trazendo prejuízos para a assistência. Em outro cenário, quando há empatia em demasia, a questão emocional do profissional pode ficar comprometida, pois em meio aos sentimentos de aflição e sofrimento, o desempenho de suas atividades laborais pode acabar sendo afetado, no sentido de antecipar ações que lesionam a autonomia do paciente, ou causem prejuízos aos demais, ampliando desigualdades (Callegari et al., 2015).

"entendo que é o atendimento que envolve os profissionais, procedimentos, normas, regras e infraestrutura, que atendam as necessidades dos pacientes". Entrevistado C

Os mesmos demonstram compreender a importância de prestar um atendimento integral, sabendo se colocar no lugar do usuário. Também apontam em seus relatos que as normas, regras e infraestrutura, são fatores relevantes na prestação do cuidado. 
Porém, segundo seus estudos Oliveira et al. (2013), chamam atenção para o fato de que se faz necessário que administradores e gestores dos serviços de saúde, compreendam que não adianta adaptar a infraestrutura física, e aprimorar o ambiente, se os profissionais que compõem a instituição de trabalho, não estiverem conscientizados, quanto à indispensabilidade de remodelar suas estratégias de intervenção.

"eu entendo que atendimento humanizado, é aquele que considera a integralidade do cuidado, baseado no diálogo, atenção e carinho com os pacientes e familiares". Entrevistado D

Os enfermeiros entrevistados, ainda trazem uma questão significativa, a atenção ao paciente e aos familiares, visto que nestes momentos não somente o paciente, mas a família também pode estar fragilizada. Além disso, é importante ressaltar que os usuários possuem uma rede de apoio, na qual na maioria das vezes os familiares estão inclusos.

Identificando a família como forma de suporte para o paciente, os mesmos devem ser acolhidos e estarem cientes de tudo que deverá feito com o paciente, como meio de fortalecer a autoestima do ser doente, uma vez que o mesmo se sente respeitado e apoiado, inclusive na tomada de decisões, pertinentes ao seu tratamento.

Por outro lado, Oliveira et al. (2013), acreditam que mesmo sendo identificada como fundamental meio de suporte, para o tratamento e reabilitação do usuário, o comparecimento da família na unidade, por vezes, é percebida como um entrave para o efetivo seguimento das atividades laborais dos profissionais, revelando discrepância entre seu entendimento teórico e sua performance prática.

Humanizar se traduz no acolher o paciente em seu âmago, baseado em um ato demonstrado no entendimento do paciente em sua individualidade, e na contemplação da vida. É compartilhar vivências, acolher, generosa e verdadeiramente as diferenças, transformando o ambiente de forma afável, menos inquietante, proporcionando ao paciente uma assistência mais segura e amistosa (Morais et al., 2009).

\subsection{Categoria 2: Condutas humanizadas empregadas no cotidiano:}

Neste capítulo serão apresentadas as condutas consideradas humanizadas, que os enfermeiros entrevistados aplicam em suas práticas cotidianas:

\footnotetext{
"chamar o paciente pelo nome, transmitir confiança e segurança passar informações de forma clara, evitando termos muito técnicos, respeitar o indivíduo num todo, ter empatia, se colocar no lugar'. Entrevistado A

'tratamento individualizado, atendimento realizado com empatia, respeito à intimidade e as diferenças (...).".. Entrevistado C

'bom diálogo com paciente, cuidados ao paciente (...)'. Entrevistado F

"procuro estar sempre alegre, converso com os pacientes e familiares, mantenho diálogo com respeito e atenção". Entrevistado D
}

Prezar pela dignidade e pelas particularidades do sujeito, requer muito mais que a execução de técnicas, contempla um engajamento com perspectivas direcionadas aos princípios do ser humano, possibilitando a criação de um vínculo entre profissional e paciente, contribuindo efetivamente para que o processo de recuperação da saúde, seja mais leve (Cavalcante et al., 2013).

É fundamental entender que cada pessoa possui características singulares, demandando diferentes abordagens, em seu processo de internação, por tanto entender um pouco do contexto do paciente, favorece o desempenho de êxito na assistência.

A comunicação no contexto hospitalar, oportuna um assistir genuíno ao paciente, não apenas tratando-o, pois possibilita que ele manifeste suas demandas, viabilizando a existência de uma relação interpessoal, como forma de reduzir o ciclo de 
despersonalização vivenciado pelo paciente, por meio de um cuidado integral, compreendendo o paciente em sua universalidade, e não de forma desagregada em seus compostos funcionais (Morais et al., 2009).

Para Morais et al. (2009), a interação por meio do diálogo entre profissional e paciente, se expressa como uma oportunidade na formulação de ações de cuidado humanizado. Sendo indiscutível a importância da comunicação, como um meio de alavancar a humanização do cuidado em enfermagem, pois desta forma oportuna que a equipe entenda as demandas do fato de ser paciente, quando fragilizado pela doença e sua decorrente hospitalização.

\subsection{Categoria 3: Fatores dificultantes na assistência humanizada}

Quando questionados acerca dos fatores que possam dificultar a assistência humanizada, os entrevistados em grande parte chegam à mesma conclusão:

\footnotetext{
"demanda em excesso, excessiva carga de trabalho, responsabilidade de suas ações, momentos de tensão". Entrevistado A

"sobrecarga na equipe devido a insuficiência de profissionais, e a baixa remuneração'. Entrevistado C

"sobrecarga de trabalho". Entrevistado E
}

Neste ponto a sobrecarga de trabalho, o excesso de demanda, a falta de profissionais, e a baixa remuneração foram os principais pontos abordados como fatores dificultantes na prestação de uma assistência humanizada, uma vez que impedem o profissional de dispensar um tempo para assistir as necessidades individuais de cada paciente. Desta forma o profissional se vê obrigado a atender as demais demandas expostas, priorizando o atendimento do diagnóstico principal dos indivíduos, neste sentido trazendo prejuízos a assistência, uma vez que não consegue ofertar em sua totalidade.

Em seus estudos Gallo e Mello (2009), relatam que em diversos momentos, durante suas atividades, os profissionais de saúde estão sujeitos a tensões advindas de diversas origens, sendo a interação constante com a dor e o sofrimento, o convívio com pacientes terminais, o temor de errar, e o manejo de pacientes difíceis. Além disso, também vivenciam situações complicadas em sua rotina laboral nas suas instituições de trabalho, como a reduzida remuneração, a escassa valorização da profissão, e situações de desconsideração diante das dificuldades pontuadas pela equipe.

Não obstante, enfatiza-se também a inacessível ação de humanizar o atendimento ao paciente, quando não há humanização para com o profissional. Vivenciar situações de sofrimento, dor, e morte, não é algo banal, constantemente os profissionais sofrem perante o martírio experienciado por seus pacientes, nestes momentos na ânsia de solucionar as demandas dos usuários, acabam deixando de lado suas próprias necessidades (Callegari et al., 2015).

É verídico que a humanização da assistência, subordina-se às ações intrínsecas de cada indivíduo, bem como a valorização profissional, por meio do investimento em recursos humanos advindos da instituição. Isso é, proporcionar apropriadas condições de trabalho aos profissionais, de modo que eles consigam se sentir valorizados e, assim estimulados para desempenhar suas atividades laborais (Oliveira, et al., 2013).

\subsection{Categoria 4: Entendimento acerca do atendimento humanizado, e sua contribuição na melhora do paciente.}

Nesta categoria, é perceptível que os profissionais compreendem que uma assistência humanizada contribui na melhora dos pacientes, como nas falas a seguir:

\footnotetext{
'sim, atender os pacientes de forma humanizada é satisfatório, pois o paciente passa a ter mais confiança, e receber apoio na sua saúde fisica e mental, ajudando o paciente a se recuperar de forma mais rápida". Entrevistado A "sim, o tratamento humanizado, com foco nas reais necessidades do paciente, contribui de forma determinante para acelerar o processo de cura". Entrevistado C
} 
“acredito sim que a assistência humanizada, não só contribui como é fundamental para a melhora do paciente, pois quando este está doente, se sente fragilizado, quer atenção e carinho, e se o atendimento acontece de forma humanizada, pode contribuir para que este paciente se sinta encorajado no momento de dor, se sinta valorizado e bem no lugar onde está'”. Entrevistado D

Percebemos que os profissionais são bastante enfáticos, na questão da humanização como fator contribuinte para a melhora do paciente, trazendo falas nas quais destacam que um atendimento humanizado, quando direcionado no foco das reais necessidades do paciente, pode inclusive agilizar o processo de restabelecimento da saúde. Neste cenário, o enfermeiro pode ser a peça-chave para estimular o paciente nos momentos de fragilidade, pois sabemos que o enfermeiro é quem geralmente passa a maior parte do tempo ao lado do paciente, desta forma, quando o estimula e encoraja, ele pode se sentir reconhecido e valorizado.

De certa forma os sujeitos deixam um pouco de suas características individuais nas suas atitudes, e estas demonstram princípios, sentimentos e demais particularidades que os singularizam serem humanos. A humanidade, pode se esclarecer propriamente na concretização das ações humanas, sendo elas assertivas ou não, tidas como benévolas ou maléficas (Silva et al., 2011).

\section{Considerações Finais}

Com a elaboração deste trabalho pudemos compreender ainda mais, a importância da humanização, do atendimento, e das condutas humanizadas, na enfermagem. Sendo o enfermeiro, a peça-chave para potencializar ações efetivas e positivas nos serviços de saúde.

Os resultados da pesquisa foram satisfatórios, foi evidenciado que os profissionais entrevistados entendem e significam a humanização, de acordo com suas vivências e percepções. Em grande parte, associam o conceito à empatia, pela questão de cuidar do paciente da forma que gostariam de ser cuidados, sabendo se colocar no lugar do outro, para entender e solucionar suas demandas, sejam em esferas físicas ou mentais.

Também compreendem a importância de prezar pelo diálogo, e por uma comunicação efetiva, clara, e direta. Além do atendimento individualizado, conforme as necessidades do paciente, em suas condutas decorrentes das práticas cotidianas.

Em relação às dificuldades enfrentadas no dia a dia, entendemos que infelizmente muitas vezes os enfermeiros não conseguem prestar uma real assistência humanizada, isso se deve em grande parte a fatores externos que influenciam diretamente, na atividade laboral dos profissionais. Tais como a sobrecarga de trabalho, baixa remuneração, e o excesso de demanda.

Estes fatores dificultantes, no entanto, não dependem exclusivamente dos profissionais, mas sim requerem investimentos financeiros, materiais, e humanos, por parte da gestão dos serviços hospitalares, quando entendemos isso, podemos visualizar as dificuldades trazidas pelos profissionais com maior compreensão.

De uma forma geral, constatamos que o atendimento humanizado, e suas condutas, interferem diretamente na melhora do paciente. Pois uma vez que o paciente é tratado de forma respeitosa, agradável, efetiva, no momento que sente, que pode expor suas demandas, angústias, e anseios, sem julgamentos, e também compreende que será atendido em sua totalidade, seu processo de cura e restabelecimento de saúde é acelerado. Neste cenário, se desenvolve o vínculo de confiança entre profissional e paciente, o usuário do serviço se sente valorizado, e compreendido, também pode ver no profissional enfermeiro, uma rede de apoio, confiando a ele informações e sentimentos intrínsecos, que podem levar ao profissional conhecer melhor seu paciente, suas necessidades, e as decorrentes mudanças em seu estado clínico.

Assim nesta conjuntura, não somente o paciente é beneficiado, mas também o profissional enfermeiro, pois se sente bem em estar contribuindo efetivamente na melhora do paciente, também passa a se perceber como um fator importante e fundamental no processo de restabelecimento de saúde, uma vez que percebe que o paciente confia e compartilha com ele, seu momento de vulnerabilidade e fragilidade representando um maior envolvimento do caso. 
A partir das entrevistas, avalia-se que os profissionais se apresentam satisfeitos com o trabalho que vem sendo realizado por eles, mas que ainda poderia ser melhor, se houvesse um melhor direcionamento e resolubilidade para os fatores que eles apontam como dificultantes.

Também é importante manter e oportunizar, a educação permanente e constante em saúde, abrindo espaços para uma discussão sobre o que já é feito, e o que pode ser melhorado, para o bom funcionamento dos serviços.

\section{Referências}

Alves, C. F. D. O. (2012). Saúde mental e SUS: As políticas públicas como alvo de interesses privados. Psicologia \& Saberes 1(1), 77-80. https://revistas.cesmac.edu.br/index.php/psicologia/article/view/49

Ayres, J. R. D. C. M. (2006). O cuidado e a crítica da atenção à saúde. In: DESLANDES, Suely. F(Org.). Humanização dos cuidados em saúde: conceitos, dilemas e práticas. Fiocruz.

Bardin, L. (2016). Análise de conteúdo. Edições 70.

Callegari, Rita D. C., Massarollo, Maria C. K. B., \& Santos, Marcelo J. D. (2015). Humanização da assistência à saúde na percepção de enfermeiros e médicos de um hospital privado. Revista Escola de Enfermagem da USP, 49(2), 42-47. <http://www.scielo.br/scielo.php?script=sci_arttext\&pid=S0080$62342015000800042 \& \operatorname{lng}=$ en\&nrm=iso>

Campos, Gastão W. D. S. Humanização na saúde: Um projeto em defesa da vida? (2005). Revista Interface, 9(17), 389-406, 2005. https://www.scielosp.org/article/icse/2005.v9n17/398-400/pt/.

Cavalcante, Andreia K. D. C. B., Damasceno, Clareane A. F., \& De Miranda, M. D. S. (2013). Humanização da assistência em atendimento de urgência hospitalar: percepção dos enfermeiros Revista Baiana de Enfermagem, 27(3). https://periodicos.ufba.br/index.php/enfermagem/article/view/8318/8421

Chemin, B. F. (2020). Manual da Univates para trabalhos acadêmicos. (4a ed.) Univates.

Chernicharo, Isis D. M., Freitas, Fernanda D. D. S., \& Ferreira, M. D. A. (2013). Humanização no cuidado de enfermagem: contribuição ao debate sobre a Política Nacional de Humanização. Revista Brasileira de Enfermagem, 66(4), 564-570, http://www.scielo.br/scielo.php?script=sci_arttext\&pid=S003471672013000400015\&lng=en\&nrm=iso>.

Chernicharo, Isis D. M., Silva, Fernanda D. D.; \& Ferreira, M. D. A. (2014). Caracterização do termo humanização na assistência por profissionais de enfermagem. Escola Anna Nery, 18(1), 156-162, <http://www.scielo.br/scielo.php?script=sci_arttext\&pid=S1414-81452014000100156\&lng=en\&nrm=iso

Corbani, N. M. D. S., Bretas, A. C. P., \& Matheus, M. C. C. Humanização do cuidado de enfermagem: o que é isso? (2009). Revista Brasileira de Enfermagem, 62(3), 349-354. Recuperado de https://www.scielo.br/scielo.php?pid=S0034-71672009000300003\&script=sci_abstract\&tlng=pt.

De Moura, M. D. A. A., Watanabe, E. M. M., Santos, A. T. R. D., Cypriano, S. R., \& Maia, L. F. D. S. (2014). O papel do enfermeiro no atendimento humanizado de urgência e emergência. Revista Científica de Enfermagem, 04(11), 10-17. https://www.recien.com.br/index.php/Recien/article/view/71/133.

Deslandes, S. F. (2006). Humanização dos cuidados em saúde: Conceitos, dilemas e práticas. Fiocruz.

Fernandes, F, \&Luft, C. (2000). Super dicionário da língua portuguesa. (53a ed.) Globo.

Gallo, A. M., \& Mello, H. C. D. (2009). Atendimento humanizado em unidades de urgência e emergência. Revista F@pciência, 5(1), 1-11 http://www.fap.com.br/fap-ciencia/edicao_2009_3/001.pdf

Gil, Antônio C. (2002). Como elaborar projetos de pesquisa. (4a ed.) Atlas.

Instituto Brasileiro de Geografia e Estatística - IBGE. (2020a). Cidades- Anta Gorda RS. 2020. https://www.ibge.gov.br/cidades-e-estados/rs/anta-gorda.html

Instituto Brasileiro de Geografia e Estatística - IBGE. (2020b). Cidades- Ilópolis RS. 2020. https://www.ibge.gov.br/cidades-e-estados/rs/ilopolis.htm

Ministério da Saúde. Política nacional de humanização: Humaniza SUS. 2020. https://www.saude.gov.br/saude-de-a-z/vacinacao/vacine-se/693-acoes-eprogramas/40038-humanizasus.

Morais, G. S. da N., Costa, S. F. G. da, Fontes, W. D, \& Carneiro, A. D. (2009). Comunicação como instrumento básico no cuidar humanizado em enfermagem ao paciente hospitalizado. Acta Paulista de Enfermagem, 22(3), 323-327. <http://www.scielo.br/scielo.php?script=sci_arttext\&pid=S0103$21002009000300014 \& \operatorname{lng}=$ en \&nrm=iso>.

Moreira, M. A. D. M., Lutosa, A. M., Dutra, F. B. E. D. O., Batista, J. B. V., \& Duarte, M. C. S. (2015). Políticas públicas de humanização: revisão integrativa da literatura. Ciência Saúde Coletiva, 20(10), 3231-3242, http://www.scielo.br/scielo.php?script=sci_arttext\&pid=S1413$81232015001003231 \& \operatorname{lng}=\mathrm{en} \& n r m=$ iso.

Oliveira, J. C. P. D, Oliveira, A. L. D, Morais, Francisco D. A. M, Silva, Gessione M. D. A., Silva, \& Cícero N. M. D. (2016). O questionário, o formulário e a entrevista como instrumentos de coleta de dados: vantagens e desvantagens do seu uso na pesquisa de campo em ciências humanas: In: III CONEDUCongresso Nacional de Educação. Rio Grande do Norte, 01-13.

http://www.editorarealize.com.br/editora/anais/conedu/2016/TRABALHO_EV056_MD1_SA13_ID8319_03082016000937.pdf.

Oliveira, N. E. S., Oliveira, L. M. A. C., Lucchese, R., Alvarenga, G. C., \& Brasil, V. V. (2013). Humanização na teoria e na prática: a construção do agir de 
Research, Society and Development, v. 11, n. 1, e41111121656, 2022

(CC BY 4.0) | ISSN 2525-3409 | DOI: http://dx.doi.org/10.33448/rsd-v11i1.21656

uma equipe de enfermeiros. Revista Eletrônica de Enfermagem, 15(2), 334-43, https://revistas.ufg.br/fen/article/view/17916.

Palheta, R. P., \& Costa, R. J. D. (2012). Caminhos da humanização hospitalar em Manaus: Os trabalhadores na roda. Saúde e Sociedade, 21(1), 253-264, <http://www.scielo.br/scielo.php?script=sci_arttext\&pid=S0104-12902012000500022\&lng=en\&nrm=iso>.

Praça, F. S. G. (2015). Metodologia da pesquisa científica: Organização estrutural e os desafios para redigir o trabalho de conclusão. Revista Eletrônica Diálogos Acadêmicos, 8(1), 72-87. http://uniesp.edu.br/sites/_biblioteca/revistas/20170627112856.pdf

Resolução n. 466, de 12 de dezembro de 2012. http://conselho.saude.gov.br/resolucoes/reso_12.htm

Rios, I. C. Humanização: a essência da ação técnica e ética nas práticas de saúde. (2009). Revista Brasileira de Educação Médica, 33(2), 253-261. <http://www.scielo.br/scielo.php?script=sci_arttext\&pid=S0100-55022009000200013\&lng=en\&nrm=iso>.

Silva, Fernanda D. D., Chernicharo, I. D. M., \& Ferreira, M. D. A. (2011). Humanização e desumanização: A dialética expressa no discurso de docentes de enfermagem sobre o cuidado. Escola Anna Nery, 15(2), 306-313, <http://www.scielo.br/scielo.php?script=sci_arttext\&pid=S1414$81452011000200013 \& \operatorname{lng}=$ en\&nrm=iso>.

Silva, Maria J. P. D. (2006). O amor é o caminho: Maneiras de cuidar. (3a ed.) Loyola.

Silveira, Denise T., \& Córdova, F. P. (2009). A pesquisa científica. Unidade 2, 31-42. http://www.unisalesiano.edu.br/salaEstudo/materiais/p162 603d6554/material12.pdf.

Simões, Ana L. D. A., Bittar, Daniela B., Mattos, Érika F., \& Sakai, Liliane A. (2007). A humanização do atendimento no contexto atual de saúde: Uma reflexão. REME Revista Mineira de Enfermagem, 11(1), 81-85, jan./mar. Recuperado de http://www.reme.org.br/artigo/detalhes/318.

Volich, Rubens M. Entre uma angústia a outra (1995). Boletim de Novidades Pulsional, 80, 37-45.

Waldow, Vera R., \& Borges, R. F. (2011). Cuidar e humanizar: Relações e significados. Acta Paulista de Enfermagem, 24(3), 414-418. <http://www.scielo.br/scielo.php?script=sci_arttext\&pid=S0103-21002011000300017\&lng=pt\&nrm=iso

Wei, C. Y., Gualda, D. M. R., Silva, L. C. F. P. D., \& Melleiro, M. M. (2012). A percepção de puérperas oriundas da atenção primária sobre a humanização da assistência ao parto em um hospital de ensino. O Mundo da Saúde, 36(3), 468-474, http://www.saocamilo-sp.br/pdf/mundo_saude/95/9.pdf. 